\title{
Ambiências comunicativas
}

Adilson Citelli

Professor titular do Departamento de Comunicações e Artes da ECA/USP, onde ministra cursos de graduação e pós-graduação. Orienta dissertações e teses nas áreas de Comunicação $e$ Linguagem, com ênfase nas subáreas Comunicaşão/Educaşão, Comunicaşão/Linguagem. É coeditor da revista Comunicação \& Educação, bem como pesquisador 1C do CNPq. E-mail: citelli@uol.com.br

Resumo: $O$ autor evidencia como o termo comunicação parece cada vez mais ancorado e dependente da existência de outra dimensão, onde informações, notícias e acontecimentos, aparentemente, abandonaram os fluxos interpessoais para viverem no e do exclusivo universo maquínico. Com essa ressalva, alerta sobre uma provável falsa impressão de verdade, denominando-a de sinédoque das ocorrências comunicacionais. $O$ excesso de visualidade e audição gerado pelo espalhamento dos media oferece, assim, uma espécie de ocultação, uma máscara, que termina por recobrir a própria ideia do fazer comunicativo. A apresentação, por fim, ao encaminhar os artigos desta edição indica as várias dimensões em que se pode operar com o conceito de comunicação.

Palavras-chave: comunicação, educação, educomunicação, ambiência, recepção.
Abstract: The author explains how the term Communication seems more and more grounded and dependent on the existence of another dimension, where informations, news and events, apparently abandoned interpersonal flows to live in and from the exclusive machinic universe. With that exception, he warns about a possible false impression of truth, calling it synecdoche of communication occurrences. Too much visuality and hearing generated by spreading of media thus offer a kind of concealment, a mask, which ends up coating the very idea of doing Communication. The presentation delivered in this issue indicates the various dimensions in which it is possible to operate the communication concept and its ramificantions.

Keywords: communication, education, educommunication, environment, reception.

Um dos subprodutos decorrentes do avanço tecnológico nas comunicações foi a ampliação de um sensorium plasmado nos vínculos entre a realização dos atos comunicativos e a imperiosa presença de dispositivos técnicos para mediá-los. A comunicação entre dois sujeitos parece haver se tornado possível apenas quando se interpôs entre eles algum tipo de equipamento localizado fora de extensões perceptuais como visão, audição, mecanismos fonadores etc.

A despeito de as pessoas falarem, verem, ouvirem, seguindo uma rota natural, ancestral, o termo comunicação parece cada vez mais ancorado e dependente da existência de outra dimensão, mais abrangente, espaço ocupado pelo conjunto instrumental que inclui televisão, rádio, jornal, computador. Isto é, informações, notícias, acontecimentos, aparentemente abandonaram os fluxos interpessoais para viverem no e do exclusivo universo maquínico. Trata-se, por certo, de uma falsa impressão de verdade; a ela chamaremos de sinédoque das ocorrências comunicacionais. 
comunicação \& educação • Ano XV • número 2 • maio/ago 2010

Posto de outro modo, estamos ante um conjunto técnico e tecnológico capaz, sob certas circunstâncias, de subsumir os sujeitos falantes, e que se materializa em partes, os veículos/medias/dispositivos, sem os quais ficaríamos diante do vazio, correndo o risco da danação, do mergulho no insondável mundo do silêncio. Pactua-se, portanto, que o fazer comunicativo está condenado a depender do suporte, sendo que este passa a expressar toda a comunicação.

Acompanhar o jogo de ocultação proporcionado pela sinédoque das ocorrências comunicacionais leva-nos a entender por que muitos alunos ingressantes nos cursos superiores de Comunicação (fenômeno que pode acompanhá-los até a formatura e a entrada na vida profissional) solicitam, logo nos primeiros dias de aula, o acesso aos equipamentos, aos exercícios práticos com câmeras, ilhas de edição, softwares. Tal rogativa assinala que a comunicação deixa de ser fenômeno de ordem ontológica, epistemológica, afeita a indagações e reflexões envolvendo sujeitos em processo de constituição dos sentidos, migrando para imperativos instrumentais. Torna-se compreensível, portanto, o fato de que na linguagem cotidiana o substantivo comunicação venha conhecendo, crescentemente, dimensão adjetiva, pois tendente a ser tratado como qualificador de um complexo industrial que, ao ganhar moto próprio, termina colocando-se no lugar do objeto primeiro. Em poucos termos: a comunicação é dada como instância que se manifesta nos e através dos equipamentos técnicos, e estes, por seu turno, ganham a estatura de lugares representativos de todo processo comunicativo.

Considerássemos o assunto sob ângulo maior - conquanto sobre ele não nos ocupemos no momento -, diríamos que a apropriação das ocorrências comunicacionais a partir da inflexão pela sinédoque reitera estarem os meios determinados a servir para a realização de certos fins. É curioso o resultado da operação em linha reta ancorada nos sequenciamentos da causalidade aristotélica, visto que o estandarte mais evidente da alta modernidade tremula na direção do fim dos andamentos lineares, das lógicas das causas que determinam os efeitos imediatos. O produto claro dessa autonomia das técnicas empurra os fazeres comunicativos no rumo pragmático dos determinativos instrumentais. Desnecessário especular acerca das consequências éticas resultantes desta conduta.

Em registro heideggeriano, diríamos que, se os desdobramentos da técnica formulam a essência do homem moderno, matizando os seus gestos, interferindo em seu destino, cabe atentar, ademais, para o fato de que a técnica é, ao mesmo tempo, reificação (do ente) e retificação ininterrupta do domínio por ela exercido. Em outras palavras, para se tirar proveito da técnica moderna - no fundamental, um conhecimento na produção, uma forma de saber - é imperioso desocultá-la, reconhecê-la, artifício através do qual podemos, ante ela, alcançar alguma autonomia. Sobre essa compreensão de Heidegger acerca da essência da técnica e a sua relação com o homem moderno, cabe apenas lembrar que apresenta várias camadas de complexidade, que não serão aprofundadas aqui. Apenas assinalamos o fato segundo o qual o filósofo alemão não pensa a técnica como um arranjo instrumental de aparelhos; tampouco está em seu escopo vincular técnica e desumanização e alienação. Trata-se, sobretudo, de ver 
a técnica como algo que se oferece aos homens, cumprindo a eles entendê-la. De outro modo, o que pode resultar é o homem submergir à técnica.

A tentativa de velamento da natureza técnica que regula diferentes fazeres - que não se restringe, portanto, a meios chamados, por exemplo, de rádio, televisão, computador etc. -, do cotidiano dos seres (que vestem roupas, trafegam em automóveis e ônibus, tomam remédios), passando pelas descobertas científicas (o sequenciamento genômico, a digitalização, a quebra da velocidade do som), até os arranjos econômicos (os modelos econométricos, os sistemas de gerenciamento, as tabelas para cálculo dos juros), resulta em deificação dos equipamentos. É um curioso paradoxo, pois, quanto mais se mostra e se aproxima do objeto, mais a sua natureza técnica sugere desaparecer: nos termos antes enunciados, se estabelece a ocultação. Resta a ideia de que o sujeito domina a coisa. Heidegger admite residir, neste caso, um equívoco, pois o máximo a ser alcançado pelo sujeito é tornar-se o senhor da relação com a técnica. Por esta via não é possível conceber a técnica como algo de inteiro domínio humano. Aliás, admitir tal limitação é a maneira através da qual os homens conseguem conservar alguma autonomia perante a técnica.

O excurso ajuda a problematizar os limites enfrentados por apreensões do termo comunicação, quando colocados em chave instrumental. Está em jogo uma espécie de teatro dos enganos. A estratégia da sinédoque, tomando a parte pelo todo e diluindo nas dinâmicas dos veículos os sentidos últimos dos atos comunicativos, remete o fenômeno técnico a um em si com força ilusória de instituir a complexidade das significações. $\mathrm{O}$ excesso de visualidade e audição gerado pelo espalhamento dos media oferece, assim, uma espécie de ocultação, uma máscara, que termina por recobrir a própria ideia do fazer comunicativo.

Em um momento que o Departamento de Comunicações e Artes, da Escola de Comunicações e Artes da USP, cria a sua Licenciatura em Educomunicação, curso a se iniciar em 2011, com inscrições no vestibular da Fuvest de 2010, os textos a seguir ajudam a pensar os vários desdobramentos do termo comunicação, sobretudo a merecer visagem menos mediática e mais interlocutiva, afeita às necessidades humanas de entendimento, trocas, solidariedade. Neste caso, os aportes da educação emancipadora podem ajudar a promover discussões inovadoras.

\section{ARTIGOS NACIONAIS}

No número anterior da revista Comunicação \& Educação (n. 1, 2010), e neste, Adilson Citelli apresenta e analisa os dados de pesquisa por ele realizada com jovens professores, com até 30 anos de idade, que militam no nível básico das redes municipal e estadual do ensino de São Paulo. Com o artigo Comunicação e educação: implicações contemporâneas, o autor retoma dois dos objetivos centrais da pesquisa: indagar acerca dos vínculos que os docentes mantêm com os meios de comunicação e verificar como e se existem passagens entre tais vivências mediáticas e os projetos didáticos e pedagógicos levados a termo no cotidiano da sala de aula. 
comunicação \& educação • Ano XV • número 2 • maio/ago 2010

Em O espaço da mídia na escola, Heloísa Dupas Penteado empreende análise voltada a compreender quais espaços de articulação são necessários para a criação de um profissional com conhecimentos dos campos da comunicação e da educação. E isto considerando a formação de professores em condições de promover movimentos dialógicos entre as dimensões pedagógicas e didáticas e os desafios contemporâneos trazidos pelos ecossistemas comunicativos.

Rodrigo Fontanari, tendo como referência o retrato fotográfico, desenvolve o conceito de duplo. A imagem, ao mesmo tempo, evidencia qualidade de projeção e assume, para a consciência do observador, uma dimensão autônoma, algo que sobrevive ao sujeito que vê. É este movimento paradoxal entre uma ausência que se faz presença e uma presença ausente que caracteriza a noção de duplo, discutido pelo autor a partir do filme $A$ bela Junie.

A questão da leitura vem sendo abordada de maneira muito intensa, quando se trata de relacioná-la ao papel da escola. Richard Romancini retoma o tema, mas dá a ele tratamento instigador ao vincular práticas de leitura a protocolos culturais. Ou seja, a constituição de uma competência leitora não diz respeito, apenas, a determinados procedimentos técnicos afeitos, por exemplo, às dinâmicas alfabetizadoras, requisitando, ademais, domínios interdiscursivos. $\mathrm{Ou}$, nos termos do artigo, o circuito da leitura, para completar os campos de sentidos, solicita considerar múltiplas experiências culturais vivenciadas pelo leitor. No artigo A comunicação nos empreendimentos econômicos solidários, Marília Veríssimo Veronese e Marina Rodrigues Martins propõem uma reflexão sobre o processo da comunicação na prática autogestionária em empreendimentos econômicos solidários no Brasil. As organizações investigadas localizam-se em São Leopoldo, Rio Grande do Sul.

\section{ARTIGO INTERNACIONAL}

José Sixto García e Maria Salgueiro Santiso, da Universidade de Santiago Campostela, na Espanha, desenvolvem no artigo Comunicação ambiental para o século XXI o conceito de comunicação ecológica. Entendem os autores que a ativação de estratégias comunicativas específicas pode ter papel decisivo na formação de uma opinião pública consciente e sensibilizada para os temas ambientais.

\section{ARTIGO DE GESTÃO}

Um dos maiores patrimônios culturais da cidade de São Paulo, a Biblioteca Mário de Andrade, viveu períodos de glória e decadência. Responsável pelo segundo maior acervo do país, a BMA funcionou entre as décadas de 1940 e 1960 como um centro de agregação intelectual. Adveio um tempo de queda decorrente, sobretudo, da falta de investimentos e desinteresse governamentais, além de mudanças estruturais vividas pela própria cidade. Em 2007, a BMA foi fechada para ampla reforma e busca de revitalização. O autor do artigo, Rogério Pelizzari de Andrade, demonstra que a retomada do dinamismo da Biblioteca 
depende da elaboração de um projeto que atenda a alguns pressupostos: expectativas e anseios dos usuários, integração com o entorno urbano, espaço de interação entre pessoas, recuperação do papel de centro de difusão cultural.

\section{ENTREVISTA}

O entrevistado deste número da revista Comunicação \& Educação é Francisco Whitaker. Um dos fundadores do Fórum Social Mundial, com larga atuação junto aos movimentos sociais, o ex-vereador de São Paulo discute com clareza e profundidade uma série de temas envolvendo política nacional e internacional, educação e globalização. Dedica-se, em especial, a fazer um balanço da passagem dos 10 anos do Fórum, mostrando que o evento continua voltado à construção de um mundo melhor.

\section{CRÍTICA}

No calor dos acontecimentos, Isabel Orofino analisa as estratégias mobilizadas pelo jornalismo no caso Isabella Nardoni, para alcançar as audiências. Segundo a autora, os media comerciais fazem uso de recursos próprios da narrativa ficcional e do gênero melodramático com o intuito de promover uma cenografia discursiva ampliadora dos mecanismos do espetáculo. Ademais, o texto aprofunda a compreensão do papel dos receptores nas mediações dos conteúdos veiculados pelos meios de comunicação.

\section{DEPOIMENTO}

É do maestro Flávio Pimenta a seção Depoimento deste número da nossa revista, em que mostra como a música pode ajudar a formar cidadãos. A obra por ele realizada ganhou o Brasil e o exterior, constituindo uma experiência singular de ação social que equilibra trabalho comunitário e educação profissional. Flávio Pimenta criou o grupo artístico Meninos do Morumbi, que atende mais de três mil crianças de baixa renda. Considerado pela Unesco como projeto-modelo, os Meninos do Morumbi já recebeu prêmios da Unicef, Ministério da Cultura, Câmara Americana de Comércio e Rotary Internacional, entre outros.

\section{EXPERIÊNCIA}

Márcia Perencin Tondato mostra como os projetos experimentais desenvolvidos como práticas pedagógicas com alunos de graduação nos cursos de comunicação ajudam a promover reflexão teórica e problematizar futuras atividades profissionais, visto buscarem soluções inovadoras e criativas para empresas reais. Tal experiência extracurricular pode ser implementada através de agências experimentais. 
comunicação \& educação • Ano XV • número 2 • maio/ago 2010

\section{POESIA}

Adilson Citelli e Cristine Vargas selecionaram dois textos que tematizam o mundo do trabalho. O operário em construção, de Vinicius de Moraes, e Construção, de Chico Buarque de Hollanda. Em ambos os casos, revelam-se produções que tanto recorrem a certa problemática social como promovem fatura literária de alta qualidade.

\section{SERVIÇOS}

Deusdédit Carneiro Leite Filho, arqueólogo diretor do Centro de Pesquisa de História Natural e Arqueologia do Maranhão, apresenta esta instituição como uma das mais importantes na promoção, valorização e preservação do acervo patrimonial maranhense, sobretudo no que tange à cultura material e tradições dos povos indígenas daquele estado. O CPHNAMA, junto com as pesquisas nas áreas de Paleontologia, Arqueologia e Etnologia, realiza ações voltadas à educação patrimonial através da elaboração, organização e execução de exposições, eventos culturais, mostras, seminários, palestras e aulas direcionadas a públicos diferenciados.

\section{VIDEOGRAFIA}

Maria Ignês Carlos Magno mostra, a partir de três filmes - Diários de motocicleta, de Walter Sales, Che: Part One e Che: Part Two (A guerrilha), de Steven Soderbergh, todos enfocando aspectos da trajetória vivencial e política de Che Guevara -, como é possível à escola trabalhar determinados conteúdos, sem recorrer, necessariamente, aos livros didáticos.

\section{BOLETIM BIBLIOGRÁFICO}

As subseções de Bibliografia sobre telenovela brasileira e Bibliografia sobre Comunicação e Educação apresentam livros, teses e dissertações sobre as respectivas temáticas. Endereços úteis na internet pode contribuir para incrementar as tarefas cotidianas dos professores.

\section{ATIVIDADES EM SALA DE AULA}

Ruth Ribas Itacarambi propõe projetos pedagógicos a serem desenvolvidos em sala de aula com alunos do Ensino Fundamental e Médio, utilizando artigos publicados neste número. 